\title{
Essential role for Stat5 in the neurotrophic but not in the neuroprotective effect of erythropoietin
}

\author{
N Byts ${ }^{1,2}$, A Samoylenko ${ }^{1}$, T Fasshauer $^{1}$, M Ivanisevic ${ }^{1}$, L Hennighausen $^{3}$, H Ehrenreich ${ }^{2}$ and A-L Sirén ${ }^{*, 1}$
}

The transcription factors signal transducer and activator of transcription $5 a$ and $5 b$ (Stat5) are activated by the neuroprotective and neurotrophic cytokines, erythropoietin (EPO) and growth hormone (GH). Here, we show a dissociation of the intracellular pathway mediating the protective effect of EPO against glutamate toxicity from that needed for its neurotrophic activity using hippocampal neuronal cultures from Stat5a/b-knockout $\left(\mathrm{Stat}^{-I-}\right)$ mouse fetuses. Both pretreatment and post-treatment with EPO counteracted glutamate-induced cell death in Stat5 ${ }^{+I+}$ and Stat $5^{-I-}$ neurons. Acute pharmacological inhibition of Janus kinase 2 (JAK2)/Stat signalling had no effect on EPO neuroprotection, whereas inhibition of phosphatidylinositol-3' kinase (PI3K)/Akt pathway abolished the protective effect of EPO in both Stat5 ${ }^{+I+}$ and Stat5 $5^{-I-}$ neurons. GH effectively protected Stat5 ${ }^{+I+}$ cells against glutamate toxicity but had no effect in Stat $5^{-I-}$ neurons or in Stat5 ${ }^{+I+}$ neurons treated with JAK2/Stat or PI3K inhibitor. EPO and GH stimulated neurite outgrowth and branching of Stat $5^{+l+}$ neurons by activating PI3K/Akt signalling but had no trophic effect in Stat $5^{-I-}$ cells. We conclude that in hippocampal neurons, Stat 5 is not required for neuroprotection by EPO but is together with Akt essential for its neurotrophic activity. Both Stat5 and Akt are needed for neuroprotective and neurotrophic signalling of $\mathrm{GH}$ in neurons.

Cell Death and Differentiation (2008) 15, 783-792; doi:10.1038/cdd.2008.1; published online 8 February 2008

The transcription factors signal transducer and activator of transcription $5 \mathrm{a}$ and $5 \mathrm{~b}$ (Stat5) control cell fate decisions such as differentiation, proliferation and apoptosis. ${ }^{1}$ Stat5 mediates cellular response to cytokines, growth factors and hormones. ${ }^{1}$ Upon binding to their membrane receptors, growth factors such as erythropoietin (EPO) and growth hormone $(\mathrm{GH})$ activate Janus kinase 2 (JAK2), causing activation of Stat5 by its phosphorylation, dimerization and translocation to the nucleus, where Stat5 induces expression of various antiapoptotic genes. ${ }^{1}$ Indicative of an impaired functioning of EPO and $\mathrm{GH}$ receptor-associated signalling, Stat5a/b-knockout mice $\left(\right.$ Stat $\left.5^{-/-}\right)$are severely anaemic and growth retarded and the vast majority die perinatally. ${ }^{2}$

Stat5 is expressed in the developing nervous system., Recent studies suggest a role for Stat5 in neuronal migration and axon guidance in the developing brain $^{3}$ and a novel therapeutic potential for constitutively active Stat5 in reducing axonal outgrowth defects in spinal muscular atrophy-like motor neurons. ${ }^{5}$ Since activation of Stat5 in neurons accompanies the antiapoptotic and neuroprotective effects of EPO in vitro and in vivo, ${ }^{6-12}$ Stat5 has been suggested to mediate the protective effects of EPO in neuronal cells. Nevertheless, the molecular mechanisms of EPO receptor (EPOR) activation in neurons are complex, as multiple neuroprotective signalling pathways are activated downstream of EPOR/JAK2. In addition to Stat5, best character- ized from these are the phosphatidylinositol-3' kinase (PI3K)/ Akt, nuclear factor- $\kappa \mathrm{B}$ and Ras/mitogen-activated protein kinase (Ras/MAPK) pathways. ${ }^{6-8,10,12-17}$ To directly test whether activation of Stat5 in neurons is essential for EPO actions, we examined the neuroprotective and neurotrophic effects of EPO in hippocampal neuronal cultures isolated from Stat $5^{-/-}$and Stat $5^{+/+}$mouse fetuses, ${ }^{2}$ after acute abrogation of JAK2/Stat phosphorylation by the newly available pathway-specific inhibitor, cucurbitacin I. ${ }^{18,19}$ Since Stat5 has been shown to be crucial for intracellular signalling and the somatotrophic effects of $\mathrm{GH},{ }^{20,21}$ we studied in parallel its effects in the Stat5 $5^{-/-}$and Stat5 $5^{+/+}$neurons.

\section{Results \\ Reduced vulnerability to glutamate-induced toxicity of Stat5-deficient neurons. The basal cell death of hippocampal neurons from embryonal day 18 (E18) Stat5 ${ }^{-1-}$ and Stat5 ${ }^{+/+}$mice was not different on day 9 (DIV9) ( $5 \pm 1 \%, n=17$ and $5 \pm 1 \%, n=19$, respectively) or on day 12 (DIV12) ( $9 \pm 2 \%, n=11$ and $8 \pm 2 \%, n=11$, respectively). We next examined the vulnerability of Stat $5^{-1-}$ and Stat5 $5^{+1+}$ neurons to excitotoxicity by monitoring cell death $24 \mathrm{~h}$ after a toxic glutamate $(200 \mu \mathrm{M}$ for $15 \mathrm{~min})$ pulse. Cell death after glutamate challenge in both Stat5 ${ }^{+1+}$ and Stat $5^{-1-}$ neurons}

\footnotetext{
${ }^{1}$ Section of Experimental Neurosurgery, Department of Neurosurgery, University of Würzburg, Josef-Schneider-St. 11, 97080 Würzburg, Germany; ${ }^{2}$ Division of Clinical Neuroscience, Max-Planck-Institute of Experimental Medicine, Hermann-Rein-St. 3, 37075 Göttingen, Germany and ${ }^{3}$ Laboratory of Genetics and Physiology, National Institute of Diabetes, Digestive and Kidney Diseases, National Institutes of Health, Bethesda, MD 20892, USA

*Corresponding author: A-L Sirén, Department of Neurosurgery, University of Würzburg, Josef-Schneider-St 11, 97080 Würzburg, Germany. Tel: + 4993120124579 ; Fax: + 49931201 24140; E-mail: siren.a@nch.uni-wuerzburg.de

Keywords: process length; ifenprodil; D-AP-5; cucurbitacin I; LY294002; NMDA

Abbreviations: D-AP-5, D-(-)-2-amino-5-phosphonopentanoic acid; DIV, days in culture; E, embryonic day; EPO, erythropoietin; EPOR, EPO receptor; GH, growth hormone; JAK2, Janus kinase 2; NMDA, N-methyl-D-aspartate; NR2A, NMDA receptor subunit 2A; NR2B, NMDA receptor subunit 2B; PI3K, phosphatidylinositol-3' kinase; Stat, signal transducer and activator of transcription

Received 02.3.07; revised 15.10.07; accepted 07.1.08; Edited by D Kaplan; published online 08.2.08
} 
was characterized by necrosis, with only $20 \pm 5 \%(n=6)$ of the cells showing features of apoptosis by staining for cleaved caspase-3. The excitotoxicity by glutamate was mediated entirely by stimulation of the $N$-methyl-D-aspartate (NMDA) receptors, since both the non-competitive NMDAR channel blocker, MK-801, and the competitive NR2 antagonist, D-(-)-2-amino-5-phosphonopentanoic acid (D-AP-5), effectively blocked glutamate toxicity in all conditions (Figure 1). Surprisingly, the Stat $5^{-1-}$ cells were less vulnerable than the wild-type cells to glutamate-induced cell death on DIV9 (Figure 1). An altered cellular composition of the cultures did not account for the increased resistance to glutamate toxicity in Stat5 ${ }^{-1-}$ cells, as the proportion of astrocytes in Stat5 ${ }^{-1-}$ and Stat5 $5^{+/+}$cultures on DIV9 was equally low and thus an enhanced trophic support by astrocytes in Stat5 ${ }^{-1-}$ neurons was unlikely (Figure 2).

Since the vulnerability of hippocampal neurons to glutamate is known to increase with increasing days in vitro due to developmentally regulated changes in the composition of the NMDA receptors from predominantly NR1-NMDA receptor subunit 2B (NR2B) in young to a mixed NR1-NMDA receptor subunit 2A (NR2A) and NR1-NR2B oligomers in more mature neurons, ${ }^{22,23}$ we compared the protective effect of NR2B subunit-specific blocker, ifenprodil, against glutamate toxicity in younger and older cultures. Typical to the more immature character of the neurons on DIV9, glutamate toxicity in both Stat5 ${ }^{+1+}$ and Stat5 $5^{-1-}$ neurons was completely blocked by ifenprodil (Figure 1). On DIV12, Stat5 ${ }^{-1-}$ and Stat5 $5^{+/+}$ neurons were equally vulnerable to glutamate (Figure 1), but the ifenprodil-sensitive proportion of the glutamate toxicity in Stat $5^{-1-}$ neurons remained higher than that in wild-type cells (57 $\pm 6 \%$ versus $26 \pm 3 \%$, respectively, $P<0.001, n=7$ ), suggesting a delayed maturation of the neuronal NMDA receptor expression in Stat5-deficient cells.

Preventive effect of EPO but not of GH against glutamate toxicity in Stat5-deficient neurons. To explore the importance of functional Stat5 for the neuroprotective and neurotrophic effects of EPO and $\mathrm{GH}$, we investigated their ability to protect neurons against glutamate-induced cell death in primary hippocampal neuronal cultures from Stat5 ${ }^{-1-}$ and Stat5 $5^{+/+}$mice. Both growth factors were applied to the

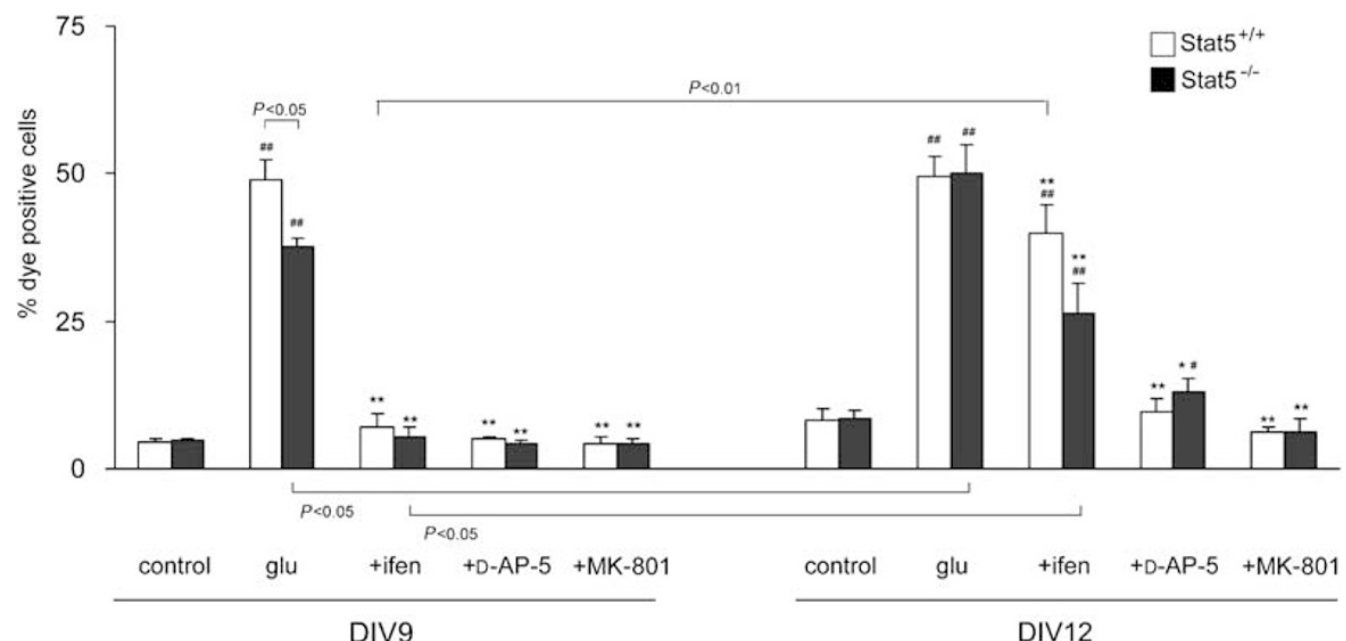

Figure 1 Glutamate toxicity in $\mathrm{E} 18 \mathrm{Stat} 5^{+/+}$and Stat $5^{-1-}$ hippocampal neurons at DIV9 and DIV12. Cells were treated with glutamate (200 $\mu \mathrm{M}$ for $\left.15 \mathrm{~min}\right)$ or medium (control) in the absence or presence of NMDA receptor antagonists, ffenprodil $(10 \mu \mathrm{M})$, D-AP-5 $(50 \mu \mathrm{M})$ and MK-801 $(10 \mu \mathrm{M})$, and cell death was assessed $24 \mathrm{~h}$ later by Trypan blue dye uptake. Antagonists were added to the medium 20 min prior to glutamate. Data are expressed as mean \pm S.E.M. (for control and glutamate $n=17$ at DIV9, $n=11$ at DIV12, and for all other conditions $n=4-6$; ${ }^{\#} P<0.05$, ${ }^{\# \#} P<0.01$ versus control; ${ }^{*} P<0.05,{ }^{\star \star} P<0.01$ versus glutamate)
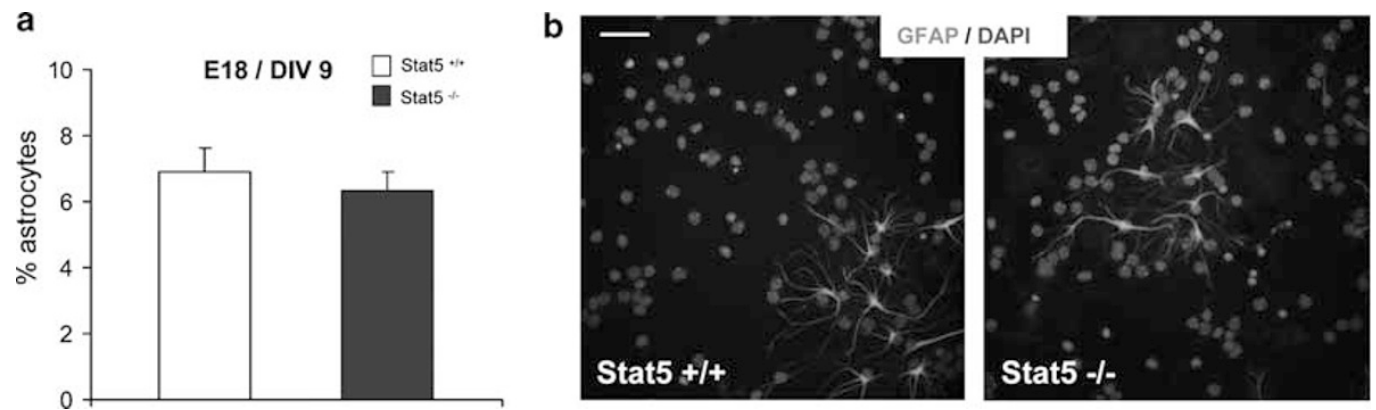

Figure 2 Astroglial contamination of Stat5 $5^{+/+}$and Stat5 ${ }^{-1-}$ E18/DIV9 hippocampal neuronal cultures. (a and $\left.\mathbf{b}\right)$ Neuronal cultures were immunostained for GFAP and the percentage of astrocytes was calculated as a ratio between GFAP-positive cells and DAPI-positive nuclei. Data are expressed as mean \pm S.E.M. $(n=4)$. $(\mathbf{b})$ Representative images, scale bar: $50 \mu \mathrm{m}$ 
cells at concentrations known to induce protection against neurotoxic agents ${ }^{24,25} 16 \mathrm{~h}$ before glutamate addition. EPO at concentrations of 1,3 and $10 \mathrm{nM}$ counteracted glutamateinduced cell death in both Stat5 ${ }^{+/+}$and Stat5 ${ }^{-/-}$neurons (Figure 3a). GH at identical neuroprotective concentrations effectively protected Stat $5^{+/+}$cells against glutamate toxicity but had no effect on cell survival in Stat5 ${ }^{-1-}$ neurons (Figure 3b). We next tested whether acute inhibition of the JAK2/Stat signalling could modify EPO and GH actions in Stat5 ${ }^{+1+}$ and $S$ tat $5^{-1-}$ neurons by pretreating the cells 20 min before EPO or $\mathrm{GH}$ administration with cucurbitacin I $(3 \mu \mathrm{M})$, a selective inhibitor of JAK2/Stat, which inhibits phosphorylation of JAK2/Stat but does not block JAK2 kinase activity and subsequent activation of PI3K/Akt or Ras/MAPK pathways. ${ }^{18,19}$ The JAK2/Stat inhibitor had no effect on EPO-induced protection against glutamate toxicity but completely prevented the protective effect of $\mathrm{GH}$ (Figure 3c).

Since the protective action of EPO was independent of Stat5, we next elucidated the impact of inhibition of the PI3K/ Akt pathway on this action. The PI3K inhibitor, LY294002 $(30 \mu \mathrm{M})$, slightly decreased baseline cell viability on DIV9 but did not further enhance cell death in glutamate-treated neurons (Figure 3d). The protective effect of EPO was completely abolished in both Stat $5^{+1+}$ and Stat $5^{-1-}$ cells by LY294002 (Figure 3d). LY294002 also inhibited the cytoprotective action of $\mathrm{GH}$ in Stat5 ${ }^{+/+}$neurons (Figure 3d). These data indicate that PI3K/Akt, but not the JAK2/Stat5 pathway, is necessary for the prevention of glutamate-induced cell death by EPO and that both signalling pathways are involved in the protective effect of $\mathrm{GH}$.

\section{Neuroprotective effect of acute post-treatment with EPO but not with GH against glutamate toxicity in Stat5-} deficient neurons. Since pretreatment with EPO and $\mathrm{GH}$ $16 \mathrm{~h}$ before the exposure of cells to the toxic glutamate pulse may be viewed as preconditioning inducing protective mechanisms different from those mediating acute neuroprotection, we studied the potential of EPO and $\mathrm{GH}$ to protect neurons against glutamate upon acute posttreatment after the toxic glutamate pulse. In Stat5 $5^{+1+}$ neurons, both EPO and $\mathrm{GH}$ reduced glutamate-induced cell death when added into the cultures $20 \mathrm{~min}$ after the glutamate pulse (Figure $4 \mathrm{a}$ and b). Again, acute posttreatment with EPO was neuroprotective in both Stat5 $5^{+1+}$ and $S t a t 5^{-1-}$ neurons, and in wild-type cells in which the JAK2/Stat signalling had been acutely disabled by cucurbitacin I, whereas $\mathrm{GH}$ protected only Stat5 $5^{+1+}$ neurons but not Stat5 ${ }^{-/-}$neurons or Stat5 $5^{+/+}$neurons in the presence of cucurbitacin I (Figure $4 \mathrm{~b}$ and $\mathrm{c}$ ).

Since the acute neuroprotective effect of EPO was also independent of Stat5, we tested whether LY294002 (30 $\mu \mathrm{M})$ could modify this effect. The protective effect of EPO was
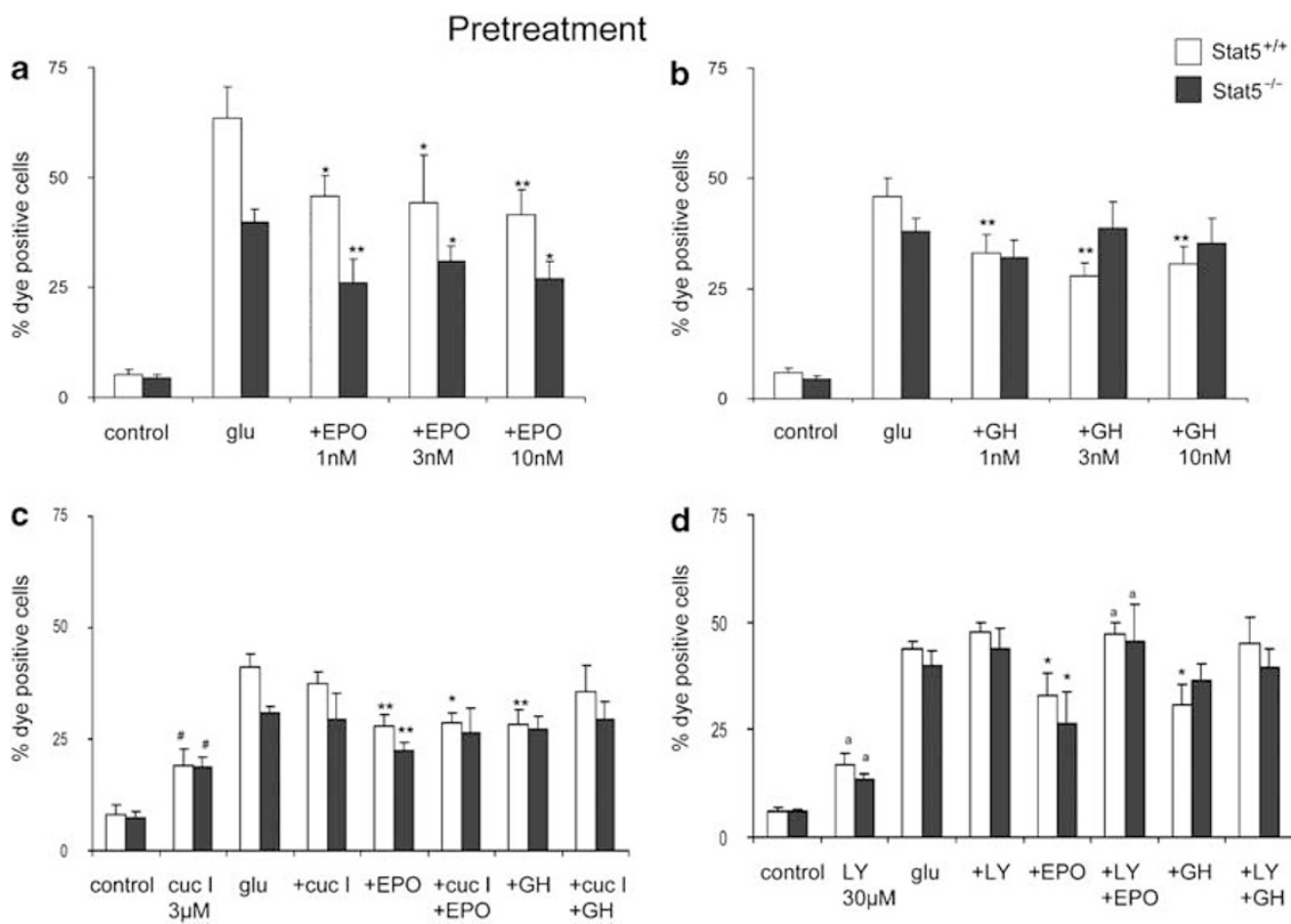

Figure 3 Effect of pretreatment with EPO or GH on glutamate toxicity in E18/DIV9 Stat5 ${ }^{+1+}$ and Stat5 $5^{-1}$ E18 hippocampal neurons. (a and b) Neuronal cultures were exposed to increasing concentrations of EPO (a) or GH (b) (1-10 nM) or vehicle $16 \mathrm{~h}$ prior to glutamate insult ( $200 \mu \mathrm{M}$ for $15 \mathrm{~min})$. Percentage of dead cells was quantified $24 \mathrm{~h}$ later by Trypan blue dye exclusion. Pretreatment with EPO effectively prevented glutamate-induced injury in both Stat5 $5^{+1+}$ and Stat5 ${ }^{-/-}$neurons, while $\mathrm{GH}$ neuroprotection was lost in Stat $5^{-1-}$ cells. (c and d) Neuronal cultures were treated with vehicle or the selective JAK2/Stat inhibitor, cucurbitacin I $(3 \mu \mathrm{M})$ (c), or selective PI3K inhibitor, LY294002 $(30 \mu \mathrm{M})(\mathbf{d}), 20$ min before the addition of growth factors (EPO/GH). Maximal neuroprotective dose of EPO $(1 \mathrm{nM})$ and $\mathrm{GH}$ ( $3 \mathrm{nM})$ was used. After $16 \mathrm{~h}$ incubation, the cells were exposed to glutamate $(200 \mu \mathrm{M}$ for $15 \mathrm{~min})$. Cell death was evaluated $24 \mathrm{~h}$ later. While cucurbitacin I failed to block EPO-induced neuroprotection but suppressed GH effect in Stat5 $5^{+1+}$ neurons in a manner that resembled knockout pattern, LY294002 effectively reversed both EPO and GH effects. Data are expressed as mean \pm S.E.M., $n=6-8$ (a and $\mathbf{b}), n=4-5$ (c and d), ${ }^{\star} P<0.05,{ }^{* \star} P<0.01$ versus glutamate, ${ }^{\mathrm{a}} P<0.05$ LY294002 versus vehicle treatment, ${ }^{\#} P<0.05$ cucurbitacin versus vehicle treatment 

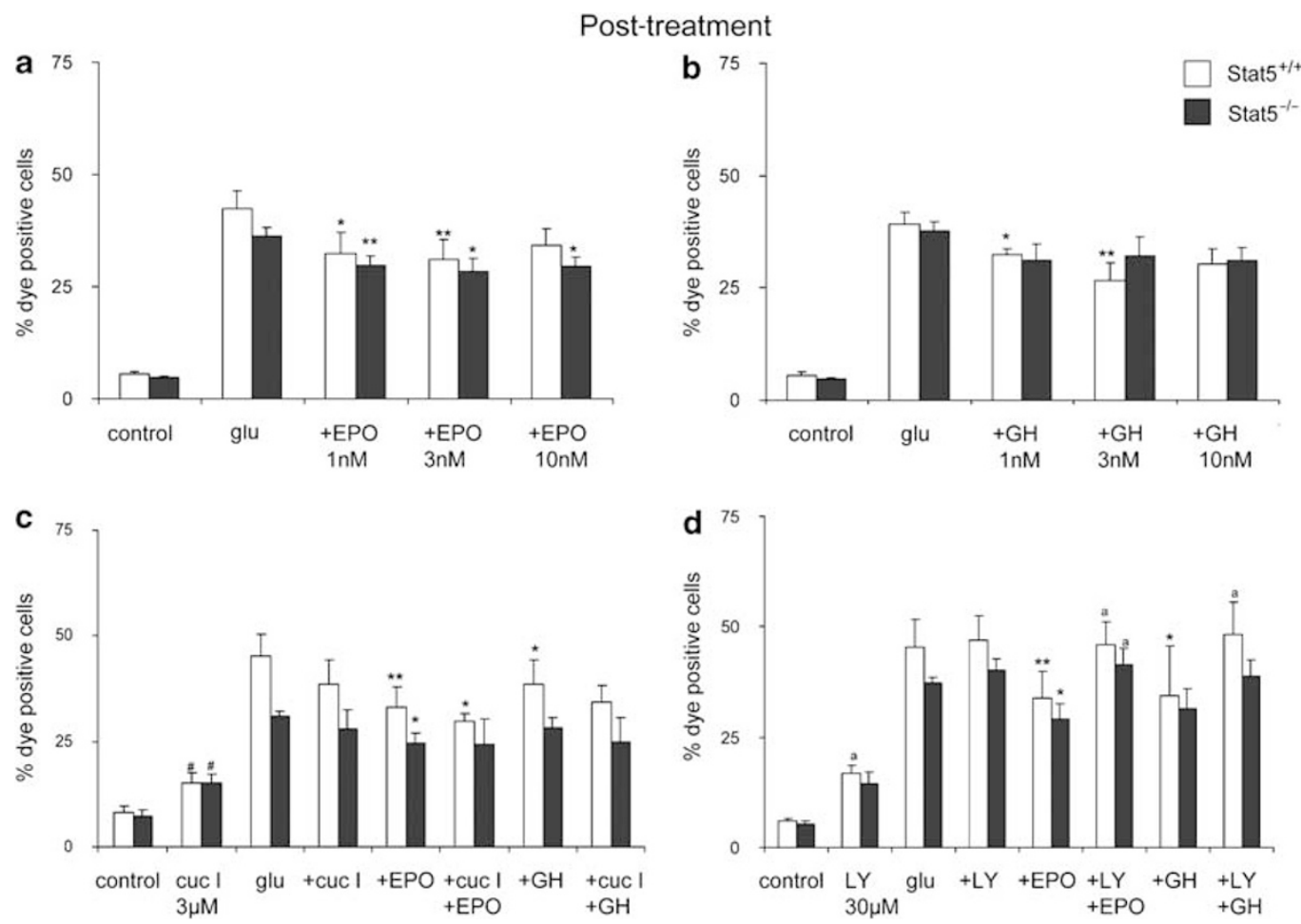

Figure 4 Effect of post-treatment with EPO or GH on glutamate toxicity in E18/DIV9 Stat5 ${ }^{+1+}$ and Stat5 ${ }^{-1-}$ hippocampal neurons. (a and $\left.\mathbf{b}\right)$ EPO (a) or GH (b) in indicated concentrations or vehicle was added to the medium $20 \mathrm{~min}$ after glutamate ( $200 \mu \mathrm{M}$ for $15 \mathrm{~min}$ ). Percentage of dead cells was quantified $24 \mathrm{~h}$ later by Trypan blue dye exclusion. Post-treatment with EPO significantly protected Stat5 $5^{+1+}$ and Stat5 $5^{-1-}$ neurons, while GH was not effective in knockout cells. (c and d) Neurons were treated with vehicle or the selective JAK2/Stat inhibitor, cucurbitacin I (3 $\mu \mathrm{M})(\mathbf{c})$, or selective PI3K inhibitor, LY294002 $(30 \mu \mathrm{M})(\mathbf{d})$, immediately after glutamate insult $(200 \mu \mathrm{M}$ for $15 \mathrm{~min}$ ) and $20 \mathrm{~min}$ before exposure to growth factors (EPO/GH). Maximal neuroprotective dose of $\mathrm{EPO}(1 \mathrm{nM})$ and $\mathrm{GH}(3 \mathrm{nM})$ was used. Cell death was determined $24 \mathrm{~h}$ later. In the presence of cucurbitacin I, EPO prevented glutamate-induced cell death in Stat5 ${ }^{+1+}$ and Stat $5^{-1-}$ cells, while GH was not effective. EPO and GH neuroprotection was blocked after treatment with LY294002 in cells of both genotypes. Data are expressed as mean \pm S.E.M. $\left(n=4-6,{ }^{*} P<0.05,{ }^{* *} P<0.01\right.$ versus glutamate, ${ }^{a} P<0.05$ LY294002 versus vehicle treatment, ${ }^{\#} P<0.05$ cucurbitacin versus vehicle treatment)

completely abolished in both Stat5 $5^{+/+}$and Stat5 $5^{-1-}$ cells after treatment with LY294002 (Figure 4d). LY294002 also reduced the neuroprotective action of $\mathrm{GH}$ in Stat5 $5^{+/+}$ neurons (Figure 4d). These data indicate that PI3K/Akt signalling is needed not only for EPO preconditioning but also for acute neuroprotection by EPO and that both Akt and JAK2/Stat5 are involved in protective effects of $\mathrm{GH}$.

Increased neuronal sprouting in E15/DIV3 neurons from Stat5 $5^{-I-}$ mice. We next determined neuronal sprouting in Stat5 ${ }^{+1+}$ and Stat5 $5^{-1-}$ cells by staining the cells with the neuron-specific marker $\beta$-tubulin III and counting the number of primary processes, branch points (first and second) and the length of the longest process per cell in hippocampal cultures from E15 fetuses on DIV3. The E15/DIV3 cultures showed no specific staining for astrocytic markers but were entirely neuronal with more than $99 \%$ of cells staining for $\beta$-tubulin III. Surprisingly, the number of primary neurites and first and second branch points were significantly higher in untreated Stat5 $5^{-/-}$than in Stat5 $5^{+/+}$cultures (Figure $5 \mathrm{a}$ and c) but the process length or cell size was not influenced by the genotype (Figure $5 b$ and $d$ ). These data suggest that deletion of Stat5 induces neurite outgrowth either directly or by enabling the expression of other regulatory trophic factors in E15 hippocampal neurons.
Stimulation of neurite outgrowth by EPO and GH in Stat5 ${ }^{+I+}$ but not in Stat ${ }^{-I-}$ neurons. The effect of EPO and $\mathrm{GH}$ on neurite outgrowth was next studied in $\mathrm{E} 15 \mathrm{Stat5}^{-/-}$ and Stat $5^{+/+}$neurons. As expected, EPO (1-10 nM) increased the number of primary neurites in Stat $5^{+1+}$ cells but had no effect on neuronal morphology in Stat $5^{-1-}$ cells (Figure 6a, $\mathrm{d}$ and $\mathrm{g}$ ). We further report on a stimulatory effect of $\mathrm{GH}(0.1-10 \mathrm{nM})$ on neurite initiation in Stat5 $5^{+/+}$but not in Stat $5^{-l-}$ neurons (Figure 6b, e and h).

Inhibition of PI3K/Akt signalling prevents growth factor actions in wild-type cells and suppresses neuronal sprouting in Stat ${ }^{-I-}$ neurons. Since the higher baseline of sprouting in Stat5 ${ }^{-1-}$ cells might mask trophic effects of EPO and $\mathrm{GH}$, we wanted to study whether acute inhibition of the Stat 5 by cucurbitacin I or the inhibition of Akt activation by LY294002 would reveal a different pattern of growth factor effects in Stat5 $5^{-1-}$ as compared to Stat5 $5^{+1+}$ cells. Owing to the extreme toxicity of the specific JAK2/Stat inhibitor in E15/ DIV3 neurons even at the lowest concentration capable of inhibiting JAK2 phosphorylation ${ }^{18,19}$ (Figure 7a, c and f), neurite outgrowth could not be tested in the presence of this inhibitor. A slight increase in cell death rate was also observed after treatment with LY294002 in both Stat5 ${ }^{+1+}$ and Stat $^{-1-}$ neurons, but the culture growth was not 


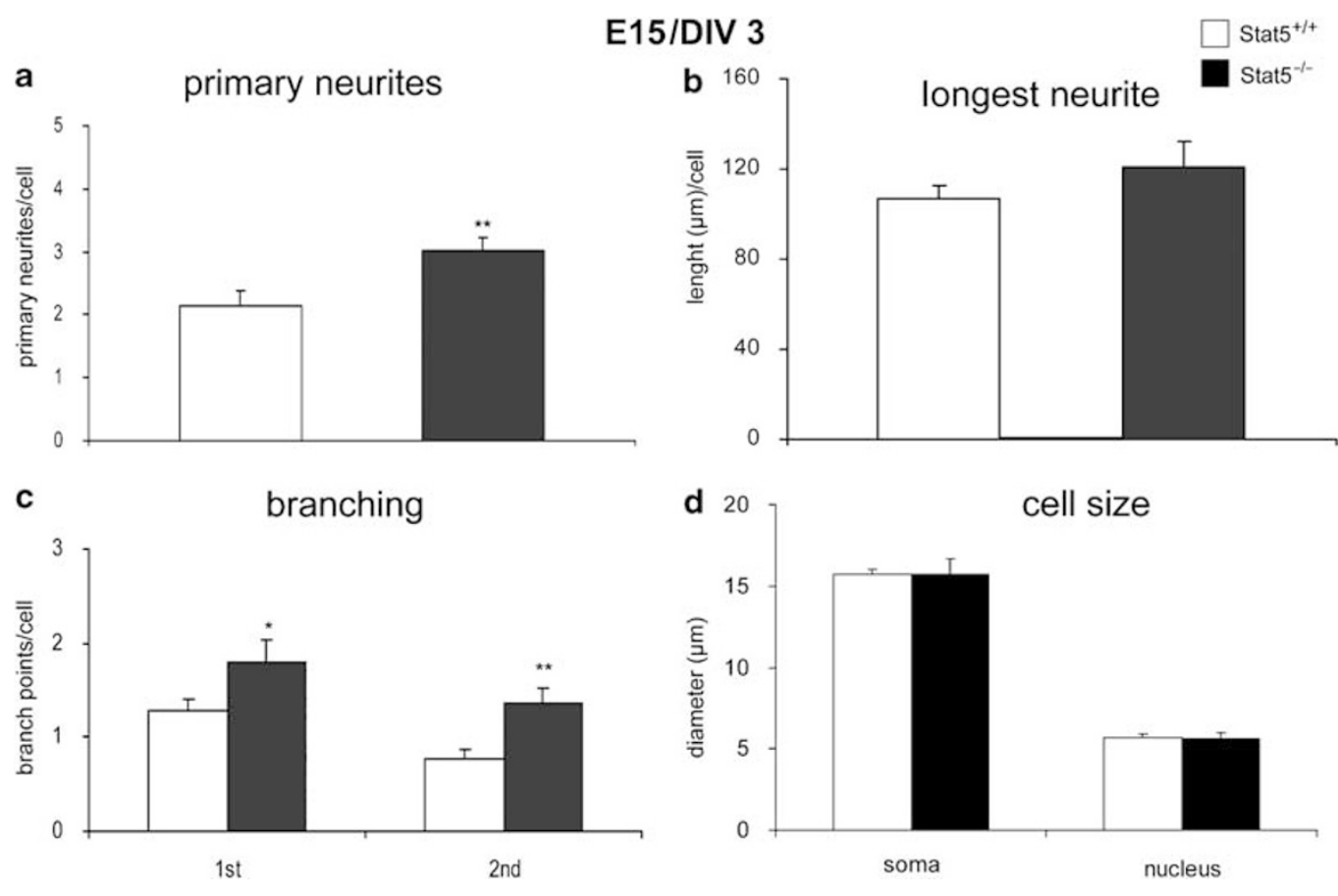

Figure 5 Morphometric analysis of Stat5 ${ }^{+/+}$and Stat5 ${ }^{-/-}$E15/DIV3 hippocampal neurons. (a-d) After 3 days in vitro, low-dense neuronal cultures were fixed, stained for the marker of immature neurons, $\beta$-tubulin III, and photographed. Different morphometrical parameters were counted on phase-contrast micrographs either manually or using SPOTAdvance image analyse software, as described in Materials and methods. Stat $5^{-1-}$ cells had a significantly greater number of primary neurites (a) and branch points of the first and second order (c) than Stat $5^{+/+}$cells, while measurement of the extent of the longest process (b) as well as quantification of soma and nucleus diameter (d) revealed no difference between the cells of two genotypes. Data are expressed as mean \pm S.E.M. $\left(n=4-6,{ }^{\star} P<0.05,{ }^{\star \star} P<0.01\right.$ Stat5 ${ }^{+1+}$ versus Stat5 $\left.{ }^{-1-}\right)$

severely affected (Figure 7a, d and g). Neurite outgrowth in Stat $5^{+I+}$ cells was not significantly impaired by LY294002, but the stimulatory effects of EPO or GH on neurite number and branching were abolished (Figure 8). In Stat5 ${ }^{-1-}$ cells, LY294002 alone significantly reduced neurite outgrowth (Figure $8 \mathrm{a}$ and $\mathrm{c}$ ). Surprisingly, the inhibitory effect on neurite branching was even more prominent when LY294002 was administered together with EPO (Figure 8c and d). These data indicate that both Akt and Stat5 are involved in neurotrophic actions of EPO and GH and that, in the absence of Stat5, Akt strongly stimulates neurite initiation and sprouting.

\section{Discussion}

When characterizing the actions of EPO and $\mathrm{GH}$ in hippocampal neurons in Stat5a/b-knockout (Stat5 ${ }^{-1-}$ ) mice, we found a differential role for Stat 5 and Akt in mediating the cytoprotective and trophic effects of EPO and $\mathrm{GH}$ : activation of Stat5 was not essential for EPO-induced protection against excitotoxicity, but together with Akt, it was required for neurotrophic activity of EPO. Both Stat5 and Akt were required for neuroprotective and neurotrophic signalling of $\mathrm{GH}$ in hippocampal neurons.

The basal cell death rate of hippocampal neurons from Stat $5^{-1-}$ and Stat $5^{+/+}$mice and control was similar both in E15 and E18 cultures. This demonstrates that Stat5, similar to $\mathrm{EPOR}^{8}$ and $\mathrm{Akt}^{26,27}$ is not essential for basal neuronal survival. We next examined glutamate-induced toxicity in Stat $^{-/-}$neurons. Glutamate, the main excitatory neurotransmitter in the mammalian brain, is in high concentrations toxic through activation of its receptors and subsequent intracellular $\mathrm{Ca}^{2+}$ overload, leading to necrotic cell death. ${ }^{23,28,29}$ The vulnerability to glutamate increases with neuronal maturation. ${ }^{23,28,29}$ In the present study, we observed a delayed vulnerability of Stat $5^{-1-}$ hippocampal neurons to glutamate. Also, the switch from the early developmental pattern of mostly NR2B-mediated to the mature $\mathrm{NR} 2 \mathrm{~A}+\mathrm{NR} 2 \mathrm{~B}-$ mediated toxicity ${ }^{23}$ was delayed in the Stat5deficient cells. Since the Stat5 pathway is commonly associated with neuronal survival, ${ }^{6-9,12}$ a Stat5-mediated toxicity upon glutamate treatment seems unlikely. The reduced vulnerability of Stat $5^{-1-}$ cells to excitotoxicity may point to a disturbed neuronal maturation in the absence of Stat5 and will be followed in ongoing studies.

To explore the importance of functional Stat5 for the neuroprotective effects of EPO and GH, we investigated their ability to protect neurons against glutamate in Stat5 $5^{-/-}$and Stat $5^{+/+}$neurons after acute abrogation of Stat5 activity using a JAK2/Stat-specific inhibitor. Both preconditioning by pretreatment with EPO $16 \mathrm{~h}$ before as well as acute posttreatment 20 min after glutamate pulse protected hippocampal neurons from the excitotoxic insult in Stat5 $5^{+/+}$neurons. These data are in agreement with the neuroprotective actions of EPO in various cell culture models. ${ }^{6,8,11,24,30}$ The mechanism of EPO-induced neuroprotection both after preconditioning and acute post-treatment involved PI3K/Akt, since the protection by EPO was effectively abolished by LY294002, regardless of the presence of functional Stat5. Therefore, we conclude that, at least in the present set-up of 

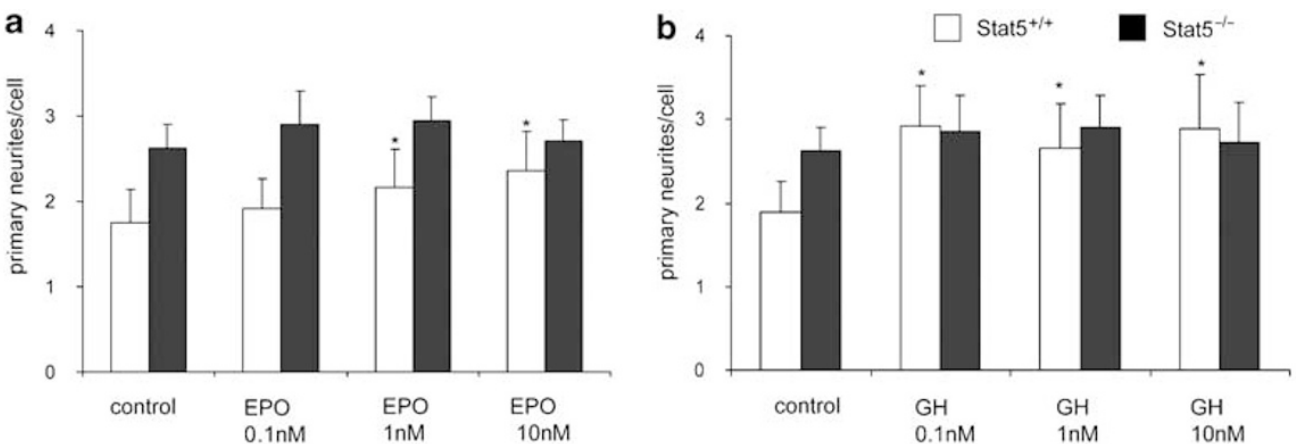

control
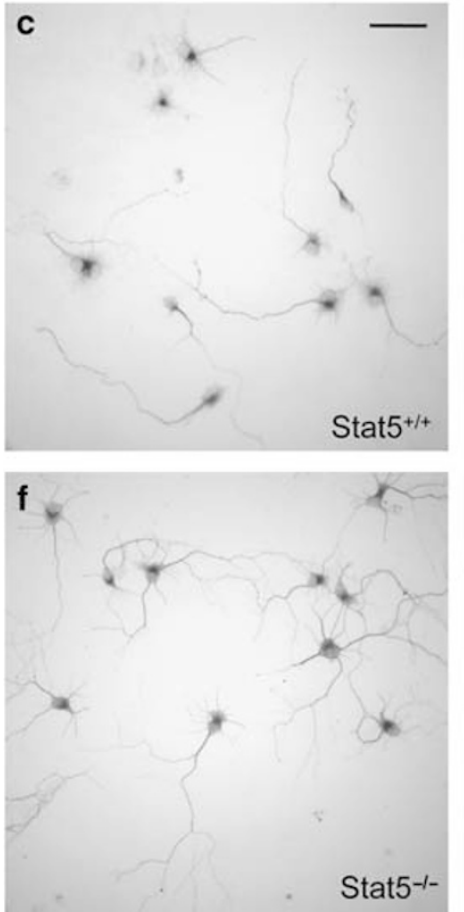
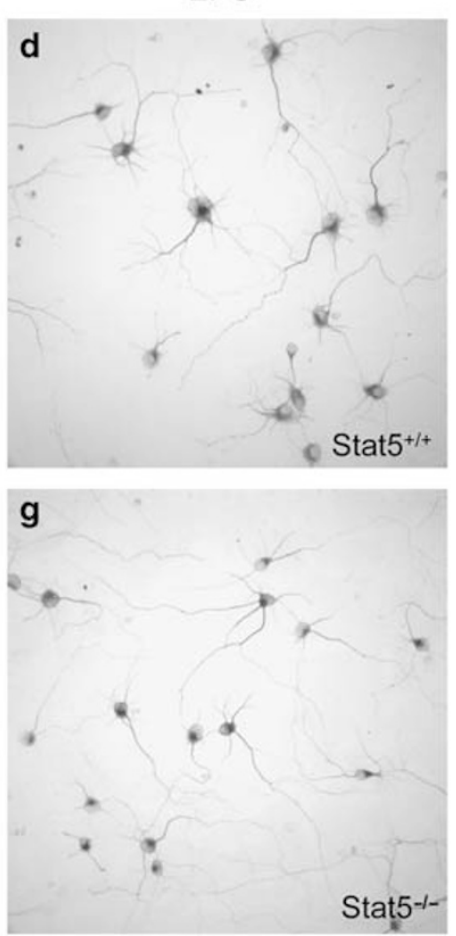

$\mathrm{GH}$
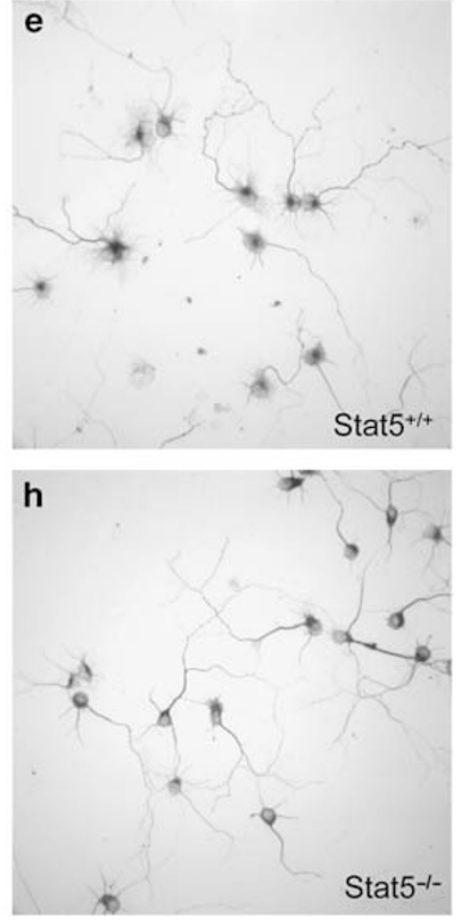

Figure 6 Effect of EPO and GH on neurite initiation of E15/DIV3 Stat5 ${ }^{+/+}$and Stat5 ${ }^{-1-}$ hippocampal neurons. (a and $\left.\mathbf{b}\right)$ Cells were cultured in the continuous presence of vehicle or EPO (a) or GH (b) added first $1 \mathrm{~h}$ after plating and then every $24 \mathrm{~h}$. On DIV3, the cells were immunostained with an anti- $\beta$-tubulin III antibody and visualized under Axiophot 2 microscope. Images were analysed as described in Materials and methods. Both growth factors increased the number of primary neurites per cell. Data are expressed as mean \pm S.E.M. ( $n=5,{ }^{\star} P<0.05$ versus control). (c-h) Representative photomicrographs of E15 neuronal cultures treated chronically for 3 days with $10 \mathrm{nM}$ EPO (d and $\mathbf{g}), 10 \mathrm{nM} \mathrm{GH}$ (e and $\mathbf{h}$ ) or vehicle (c and $\mathbf{f}$ ) (see above) and then immunostained for $\beta$-tubulin III. Scale bar: $50 \mu \mathrm{m}$

glutamate-induced toxicity in hippocampal neurons, Stat5 is not required for the protective action of EPO. The involvement of Akt in EPO-induced preconditioning has been reported in rat cortical neuronal cultures and in models of ischaemic preconditioning and acute neuroprotection in vivo. ${ }^{11,16,17,31,32}$ Similarly, the activation of Stat5 by EPO has provided indirect evidence for a contribution of Stat5 in EPO neuroprotection both in animal models of cerebral ischaemia and in neuronal cultures exposed to oxidative stress..$^{6,8-10}$ In a recent study, the EPO-induced Stat5 activity and neuroprotection was blocked by the JAK2 inhibitor, AG490. ${ }^{9}$ However, AG490 is not completely specific to Stat5 and therefore inhibition of other signalling cascades downstream of JAK2, such as PI3K/ Akt, nuclear factor- $\kappa$ B or Ras/MAPK, cannot be fully excluded. ${ }^{6,7,11,14,15,17,31}$ Interestingly, the antiapoptotic effect of EPO in neuronal cell lines has been shown to require a combinatorial activation of Akt, Stat5 and MAPK. ${ }^{7}$

$\mathrm{GH}$ effectively protected hippocampal neurons against glutamate toxicity in dose range providing protection against a neurotoxic insult in a previous study. ${ }^{25}$ Upon $\mathrm{GH}$ treatment, Stat5 is directly phosphorylated by receptor-associated JAK2, but the precise molecular mechanism of PI3K activation is not fully understood. ${ }^{33}$ Our data demonstrated an absolute requirement of functional Stat 5 for the protective effect of $\mathrm{GH}$, as both genetic ablation of Stat5 in the knockout cells and the acute inhibition of JAK2/Stat completely abolished its protective effect. Again, the cytoprotective action of $\mathrm{GH}$ was also blocked by LY294002, suggesting a combinatorial activation of Stat5 and Akt with Stat5 being upstream of Akt. 


\section{a}

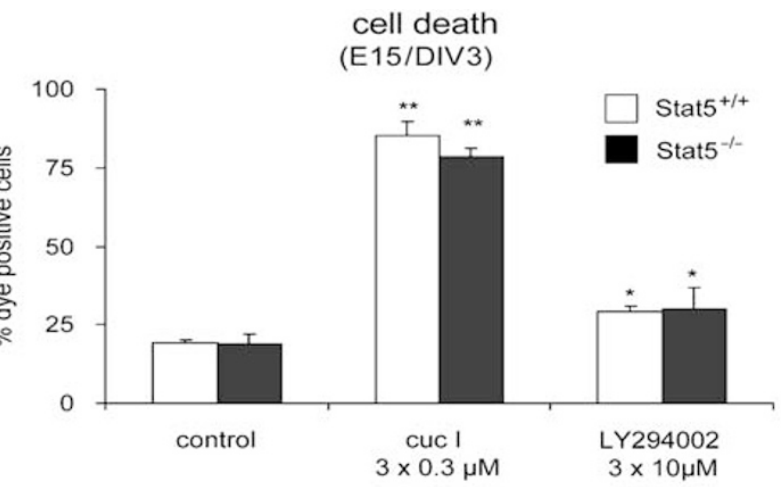

control
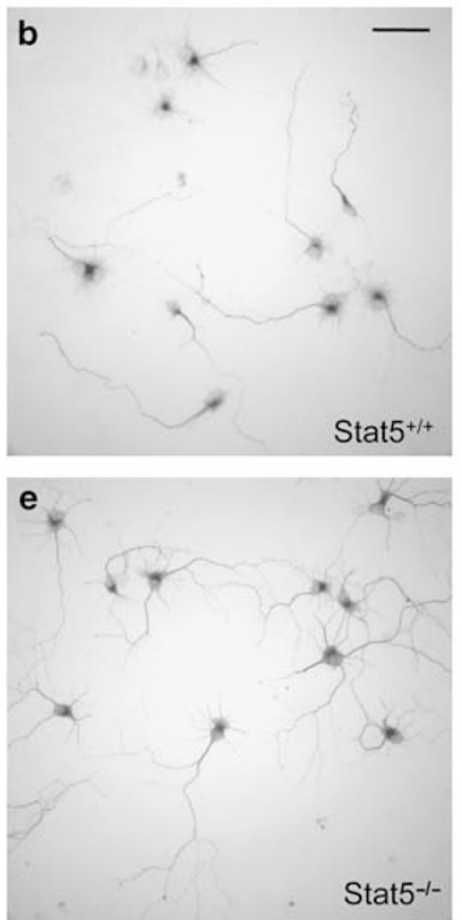

cucurbitacin I

c

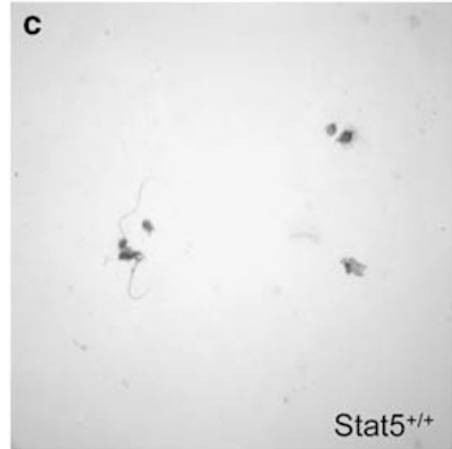

f
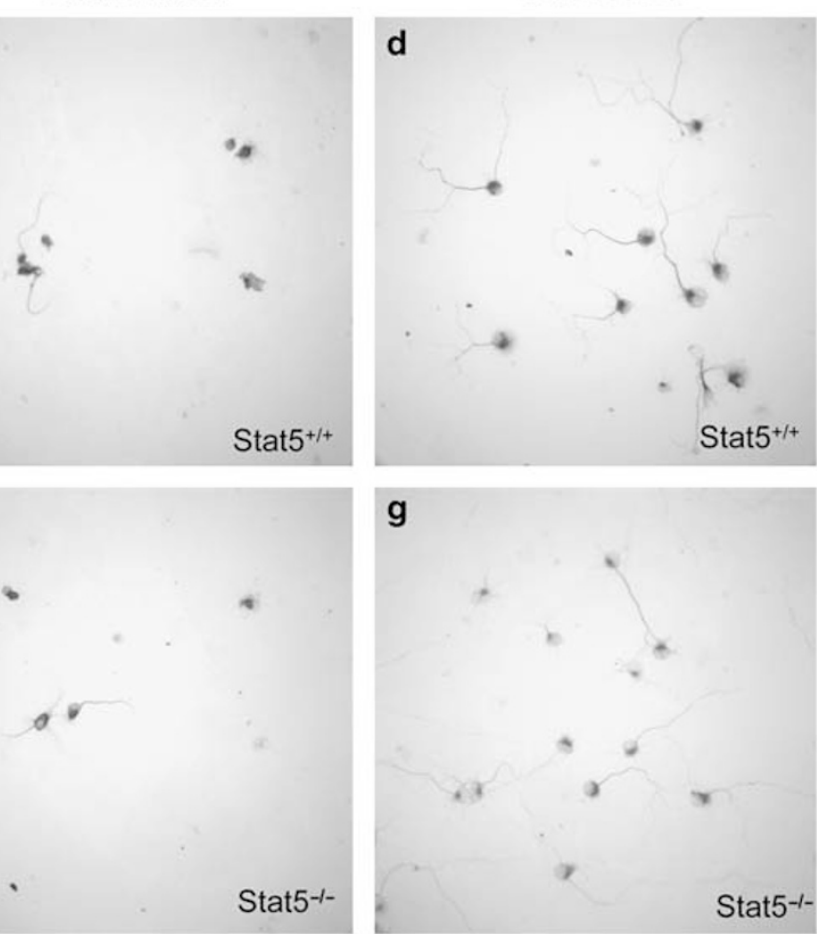

Figure 7 Effects of selective JAK2/Stat inhibitor, cucurbitacin I, and selective PI3K inhibitor, LY294002, on viability of E15/DIV3 Stat5 ${ }^{+/+}$and Stat5 ${ }^{-/-}$neurons. To test the effects of chronic treatment with inhibitors on survival of immature neurons, E15 neuronal cultures were grown in the presence of either $0.3 \mu \mathrm{M}$ cucurbitacin I or $10 \mu \mathrm{M}$ LY294002 (supplemented to the medium $1 \mathrm{~h}$ after seeding on DIV0 and then on DIV1 and DIV2). (a) Chronic treatment with cucurbitacin I induced massive cell death in both Stat5 ${ }^{+1+}$ and Stat5 ${ }^{-1-}$ cells and therefore this inhibitor was not used in further experiments. Chronic application of LY294002 led to moderate damage in cells of both genotypes. Percentage of dead cells was quantified $24 \mathrm{~h}$ later by Trypan blue dye exclusion. Data are expressed as mean \pm S.E.M. $\left(n=4-5\right.$, ${ }^{*} P<0.05$, ${ }^{\star *} P<0.01$ versus control). (b-g) Representative images of $\beta$-tubulin III-stained E15 Stat5 ${ }^{+1+}(\mathbf{b}-\mathbf{d})$ and Stat5 ${ }^{-1-}(\mathbf{e}-\mathbf{g})$ neurons chronically treated with vehicle (b and $\left.\mathbf{e}\right)$, cucurbitacin I (c and f) or LY294002 (d and g). Scale bar: $50 \mu \mathrm{m}$

In the present study, we show that EPO and GH stimulate neurite initiation and sprouting also in immature hippocampal neurons and that these effects require both Akt and Stat5. In respect to EPO, our data are in line with the previous reports. Indeed, the neurotrophic activity of $\mathrm{EPO}^{34,35}$ has been described before its cytoprotective and antiapoptotic effects were discovered in neuronal cells. ${ }^{6-8,11,24}$ EPO stimulates neurogenesis in vivo and facilitates neuronal differentiation in neuroblastoma cell lines and neural stem cell cultures. . $^{811,12,36,37}$ In regard to the findings with $\mathrm{GH}$, our data agree with a previous report demonstrating reduced brain size and sparser dendritic arborization in $\mathrm{GH}$ receptor-deficient $\left(\mathrm{GHR}^{-1-}\right)$ mice. ${ }^{38}$
Neurite initiation and sprouting were significantly increased in Stat5 $5^{-/-}$neurons as compared to Stat $5^{+/+}$cells, suggesting that Stat5 activity might negatively regulate neurite outgrowth. Therefore, we cannot exclude the possibility that the increased baseline of sprouting in Stat $5^{-1-}$ neurons might have masked the stimulatory effects of EPO and $\mathrm{GH}$. In contrast, inhibition of Akt consistently suppressed neurite initiation and sprouting in both wild-type and Stat5 ${ }^{-1-}$ neurons. The requirement of Akt for normal brain development and its crucial role in regulation of neurite outgrowth and synapse formation has been comprehensively characterized, ${ }^{26,27,39}$ whereas the role of Stat5 for neuronal differentiation has not been extensively investigated. A recent study 
a
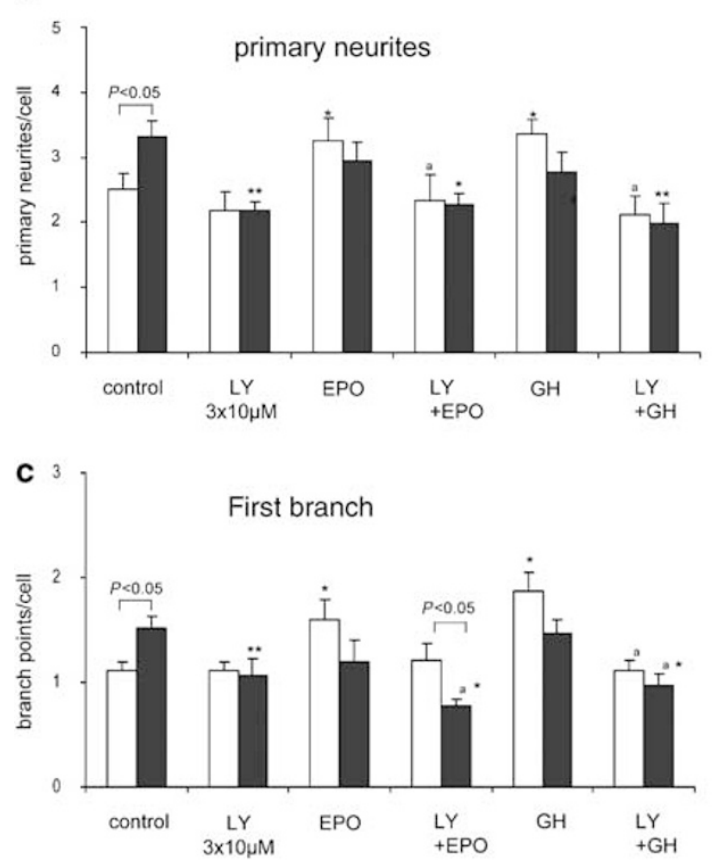
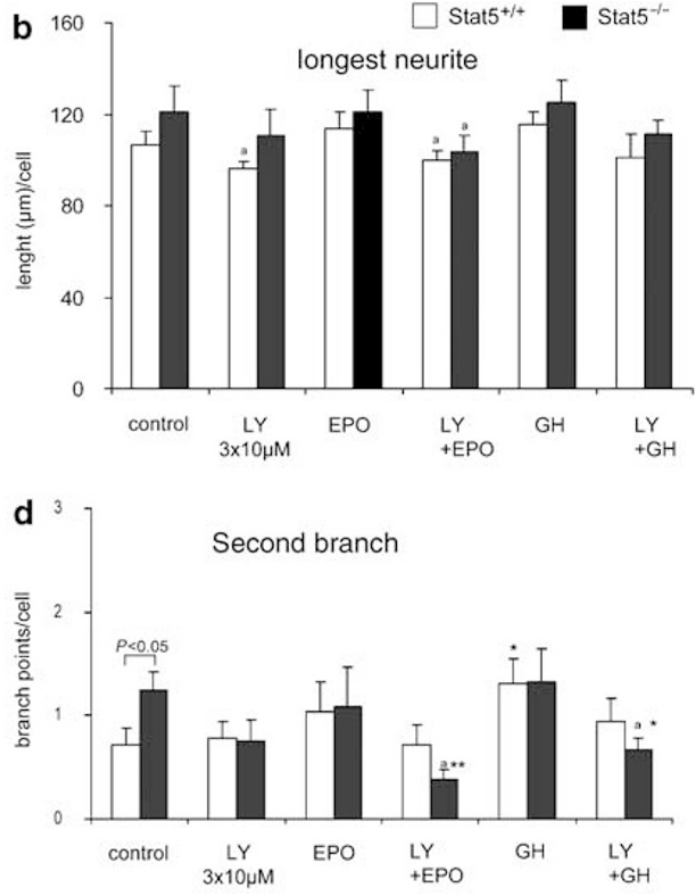

Figure 8 Morphometric analysis of E15/DIV3 Stat5 ${ }^{+/+}$and Stat5 ${ }^{-1-}$ hippocampal neurons treated with EPO or GH in the presence or absence of the PI3K inhibitor, LY294002. Neuronal cultures were continuously treated with $10 \mathrm{nM} \mathrm{EPO}$ or $10 \mathrm{nM} \mathrm{GH}$ for 3 days. LY294002 $(10 \mu \mathrm{M})$ or vehicle was added to the culture medium 20 min before the addition of each growth factor. On DIV3, the cells were immunostained with anti- $\beta$-tubulin III antibody, photographed and analysed for number of primary neurites, first and second raw branch points and the length of the longest process per cell. Both EPO and GH increased neurite initiation (a) and arborization (c and d) in Stat5 ${ }^{+/+}$neurons, without any effect on the extent of the longest process (b). LY294002 significantly blocked the effect of growth factors (a, c and d). In Stat5 ${ }^{-1-}$ cells, characterized by elaborate pattern of branching and increased amount of primary neurites, the growth factors did not cause any further neurite outgrowth or branching. Nevertheless, LY294002 reduced the number of primary neurites (a) and branch points (c and d) in Stat5 ${ }^{-1-}$ cultures equal to or less than that of Stat $5^{+1+}$ cells. Data are expressed as mean \pm S.E.M. $(n=5-6$, ${ }^{\star} P<0.05,{ }^{\star *} P<0.01$ versus control, ${ }^{a} P<0.05 \mathrm{LY} 294002$ versus vehicle treatment)

demonstrated the expression of activated Stat5 in a subset of young telencephalic neuronal cell bodies and axons during early brain development and demonstrated for the first time a requirement for Stat5 in neuronal migration and axon guidance. ${ }^{3} \mathrm{~A}$ role for Stat5 in neuronal plasticity is further suggested by the ability of a constitutively activated Stat5 construct to reduce axonal outgrowth defects in spinal muscular atrophy-like motor neurons. ${ }^{5}$

Taken together, the presence of both Akt and Stat5 seems to be required for the trophic but not for the neuroprotective effect of EPO in primary hippocampal neurons, whereas both Stat5 and Akt are necessary for GH signalling in these cells. Dissociation of the intracellular pathways for neuronal signals, which regulate cell death and differentiation/plasticity, may be decisive for growth factor activities during brain development and repair after injury.

\section{Materials and Methods}

All experiments were approved by and conducted in accordance with the regulations of the local Animal Care and Use Committee.

Chemicals. All biochemicals and enzymes were of analytical grade and were purchased from commercial suppliers: rhEPO (Janssen-Cilag, Neuss, Germany), rhGH (Immuno Tools, Friesoythe, Germany), PI3K inhibitor LY294002 (Biomol, Plymouth Meeting, PA, USA), Jak2/Stat inhibitor cucurbitacin I (Merck Biosciences, Darmstadt, Germany), L-glutamic acid sodium salt hydrate (glutamate) (Sigma, Taufkirchen, Germany), NR2B subunit-selective NMDA receptor antagonist ifenprodil tartrate salt (Sigma), NMDA receptor channel blocker dizocilpine maleate $\quad((+)$-5-methyl-10,11-dihydro-5H-dibenzo[a, d]cyclohepten-5,10-imine maleate, MK-801) (Biozol, Eching, Germany), competitive NMDA receptor antagonist D-AP-5 (Biozol).

Breeding and genotype analysis. Stat $5^{+1+}$ or Stat5 ${ }^{-1-}$ fetuses used for neuronal cultures were obtained from wild-type or hemizygote breeding, respectively. Stat5 hemizygous and wild-type mice colonies were raised from a pair of Stat5 ${ }^{+1-}$ mice kindly provided by Professor Hennighausen (Bethesda, MD, USA) and fully backcrossed on the C57BL/6 background. The generation and screening of Stat5 $5^{-1-}$ has been described by Cui et $a l^{2}{ }^{2}$ The wild-type Stat5a/b allele was detected by PCR analysis using primer $1\left(5^{\prime}\right.$-GAAAGCATGAAAGGGT TGGAG- $\left.3^{\prime}\right)$ and primer $2\left(5^{\prime}\right.$-AGCAGCAACCAGAGGACTAC-3') as a recombinant band of $450 \mathrm{bp}$, while the deleted Stat5a/b allele was determined by using a pair of primers 2 and $3\left(5^{\prime}\right.$-CCCATTATCACCTTCTTTACAG- $\left.3^{\prime}\right)$ as a band of $500 \mathrm{bp}$. Although the $S$ tat ${ }^{-1-}$ fetuses could be distinguished by their paleness and smaller size, the genotype of each Stat5 ${ }^{-1-}$ fetus used for cultures was confirmed by PCR.

Cell culture. For cell survival studies, DIV9 primary hippocampal neuronal cultures derived from E18 Stat5 ${ }^{+1+}$ or Stat5 ${ }^{-1-}$ mice were used. Briefly, after complete removal of meninges, hippocampi were dissected in warm HBSS solution (Invitrogen, Karlsruhe, Germany) supplemented with penicillin and streptomycin, and trypsinized. After mechanical trituration, the cells were plated on poly-D-lysincoated glass coverslips in four-well plates in a density of $13000 \mathrm{cell} / \mathrm{s} / \mathrm{cm}^{2}$. Neurons were cultured in MEM/B27 medium (Invitrogen) supplemented with sodium bicarbonate, sodium pyruvate, L-glutamine, penicillin, streptomycin and $0.6 \%$ glucose. Cultures were incubated at $37^{\circ} \mathrm{C}$ under $5 \% \mathrm{CO}_{2} / 95 \%$ air and $90 \%$ humidity without medium exchange up to 9 days.

To determine the effects of growth factors on neuronal morphology, primary hippocampal cells were isolated from E15 mice as described above for E18 mice. Cells were seeded in a low density of 6000 cells $/ \mathrm{cm}^{2}$ and cultured up to 3 days. 
Glutamate toxicity. Primary neurons on DIV8 or DIV11 were exposed either to the fresh medium containing $200 \mu \mathrm{M}$ glutamate or to the medium without any additions (control) for $15 \mathrm{~min}$. Afterwards, cells were returned to the original medium and cultured for an additional $24 \mathrm{~h}$. In some experiments, cultures were preincubated for 20 min with $10 \mu \mathrm{M}$ ifenprodil or $50 \mu \mathrm{M}$ D-AP-5 or $10 \mu \mathrm{M}$ MK-801 or vehicle $(0.08 \%$ ethanol). Cell death was determined $24 \mathrm{~h}$ after the toxic glutamate pulse by Trypan blue dye exclusion method.

Cell death assay. Approximately $700-1200$ cells per condition for E18 or 350600 cells for E15 neuronal cultures were counted in six distinct, non-overlapping fields of two different coverslips directly under the microscope. The percentage of neuronal cell death was determined as the ratio between the number of Trypan blue incorporating (non-viable) cells and the total number of cells.

In some experiments, apoptotic cell death was estimated as a ratio between cleaved caspase-3-positive cells and DAPI-positive nuclei (see the Immunocytochemistry section).

Counting was always performed in a blinded manner.

\section{Neuroprotective growth factor treatments}

Pretreatment. Primary neurons on DIV7 were treated with EPO or GH in the concentration range of $10^{-9}-10^{-8} \mathrm{M}$ or vehicle (PBS). In some experiments, cultures were preincubated for 20 min with $3 \mu \mathrm{M}$ cucurbitacin I or $30 \mu \mathrm{M} \mathrm{LY} 294002$ or vehicle $(0.03 \% \mathrm{DMSO})$. Sixteen hours after addition of growth factors, the cells were exposed to glutamate (see above), returned to conditioned medium and cultured for an additional $24 \mathrm{~h}$ in the continued presence of growth factors. Cell death on DIV9 was determined by Trypan blue dye exclusion method (see above) Post-treatment. Cell death was induced by glutamate as described above. Neurons were treated with EPO or GH $\left(10^{-9}-10^{-8} \mathrm{M}\right)$ or vehicle (PBS) 20 min after exposure to glutamate. In some experiments, $3 \mu \mathrm{M}$ cucurbitacin I or $30 \mu \mathrm{M}$ LY294002 or vehicle $(0.03 \%$ DMSO) was added to the cells immediately afte exposure to glutamate. Cell death on DIV9 was determined after staining with Trypan blue dye (see above).

Neurotrophic growth factor treatments. Low-density hippocampa neuronal cultures from E15 mice were used. EPO, GH (both at $10^{-10}-10^{-8} \mathrm{M}$ ) or vehicle (PBS) was added to the culture medium $1 \mathrm{~h}$ after seeding and then every $24 \mathrm{~h}$ over a 3-day period in vitro. In some experiments, the cells were treated with $0.3 \mu \mathrm{M}$ cucurbitacin I or $10 \mu \mathrm{M} \mathrm{LY} 294002$ or vehicle ( $0.01 \%$ DMSO) $20 \mathrm{~min}$ before each addition of growth factor/vehicle. On DIV3 ( $72 \mathrm{~h}$ after seeding), the cells were used for morphometric analysis.

\section{Immunocytochemistry}

GFAP staining. To estimate contamination with astrocytes, neuronal cultures prepared from E18 or E15 mice were stained with mouse anti-GFAP monoclonal antibody $(1: 500$ in $1 \%$ normal horse serum-PBS; Nova-Castra, Newcastle upon Tyne, UK) on DIV9 or DIV3, respectively. Briefly, cultures were fixed with $4 \%$ paraformaldehyde and treated with $10 \%$ normal horse serum in $0.2 \%$ Triton X-100PBS. All further incubations were performed at $37^{\circ} \mathrm{C}$ for $2 \mathrm{~h}$. Following exposure to anti-GFAP antibodies, the cultures were treated with Cy-3-conjugated goat antimouse secondary antibody (Jackson Immunotools-Dianova, Hamburg, Germany). The cells on coverslips were then washed, dried and mounted using fluorescence mounting medium containing DAPI (Vector Laboratories, Burlingame, CA, USA). Cells were visualized and photographed as described in the section 'Image acquisition and morphometric analysis of $\beta$-tubulin III-labelled neurons'. Approximately 1500-2000 nuclei of E18/DIV9 hippocampal cultures in eight distinct, non-overlapping images of two different coverslips were counted. The percentage of astrocytes was calculated as a ratio between GFAP-positive cells and DAPI-positive nuclei. E15/DIV3 cultures revealed no positive staining for GFAP. Cleaved caspase-3 staining. To estimate the percentage of apoptotic cell death after glutamate insult, DIV9 neuronal cultures from E18 mice were stained with rabbit anti-cleaved caspase-3 (Asp175) polyclonal antibody (1:100 in 1\% normal horse serum-PBS; Cell Signaling Technology, MA, USA). Briefly, $24 \mathrm{~h}$ after exposure to glutamate $(200 \mu \mathrm{M}$ for $15 \mathrm{~min}$ on DIV8) or vehicle (medium without glutamate), the cells were fixed, blocked and permeabilized as described above. Cells were incubated with primary antibody overnight at $4^{\circ} \mathrm{C}$. Cy-3-conjugated goat anti-rabbit secondary antibody was applied for $1 \mathrm{~h}$ at RT. Coverslips were then dried and mounted in fluorescence mounting medium containing DAPI. Approximately 1500-2000 nuclei per condition in eight distinct, non-overlapping fields of two different coverslips were counted directly under the microscope. The percentage of apoptotic cell death was evaluated as a ratio between cleaved caspase-positive cells and DAPI-positive nuclei.

$\beta$-Tubulin-staining. On DIV3 (72h after seeding), low-density hippocampal neuronal cultures from E15 mice were immunostained for the neuron-specific marker $\beta$-tubulin III. Briefly, cells were fixed, blocked and permeabilized as described above. After overnight incubation with mouse anti- $\beta$-tubulin III monoclonal antibody (1:1000 in 1\% normal horse serum-PBS; Sigma) at $4{ }^{\circ} \mathrm{C}$, the cells were labelled with biotinylated anti-mouse $\lg G(1: 200$ in $1.5 \%$ normal horse serum-PBS; Vector Laboratories) for $1 \mathrm{~h}$ at RT. Following incubation with $A B C$ kit reagents (mixture of avidin $\mathrm{DH}$ and biotinylated horseradish peroxidase $\mathrm{H}$; Vector Laboratories), immunoreactivity was detected by peroxidase-mediated deposition of diaminobenzidine (Sigma).

Image acquisition and morphometric analysis of $\beta$-tubulin IIIlabelled neurons. To determine the effect of growth factors on neurite morphology, $\beta$-tubulin III-stained E15/DIV3 neurons on coverslips were visualized under Zeiss Axiophot 2 microscope (Carl Zeiss, Jena, Germany) with Plan-Neofluar $40 \times 10.75$ NA objective (Carl Zeiss). Virtually, all ( $99 \%)$ cells were immunoreactive for $\beta$-tubulin III. Despite the early embryonic age of dissociation and the short time in vitro, most neurons formed primary neurites. Cells were photographed using digital camera Spot RT (Visitron Systems, Puchheim, Germany). Analysis of neurite morphology was performed manually or with the help of SPOTAdvance software (Diagnostic Instruments, München, Germany). In each experiment, 65-100 neurons from eight non-overlapping images from two coverslips were analysed in each condition. Counting was always performed in a blinded manner. The mean number of primary processes per neuron was calculated as a ratio between the total number of processes that were directly associated with soma, with the length exceeding one cell diameter, and the total number of neurons measured in one condition. The branching pattern was characterized by the number of neurite branch points of first and second order per neuron. A branch point was defined as the point of origin of at least two daughter branches with a length exceeding one cell diameter. The length of the longest neurite was measured by tracing the process from the perimeter of the soma to the farthest extent of the process. The measurement of nuclear and somatic diameter was performed in vehicle-treated conditions.

Statistical comparisons. Data, expressed as mean \pm S.E.M., were compared using SPSS 12.0 statistical analysis software. Paired or unpaired Student's $t$-tests were performed. Bonferroni correction was used for multiple comparisons. ${ }^{40} P<0.05$ was considered to be statistically significant.

Acknowledgements. This work has been supported by the DFG Graduate Program 'Neuroplasticity: From Molecules to Systems'. We thank Helga Brünner for expert help in care and breeding of the Stat5 ${ }^{+/-}$mice.

1. Ihle JN. The Stat family in cytokine signaling. Curr Opin Cell Biol 2001; 13: 211-217.

2. Cui Y, Riedlinger G, Miyoshi K, Tang W, Li C, Deng CX et al. Inactivation of Stat5 in mouse mammary epithelium during pregnancy reveals distinct functions in cell proliferation, survival, and differentiation. Mol Cell Biol 2004; 24: 8037-8047.

3. Markham K, Schuurmans C, Weiss S. STAT5A/B activity is required in the developing forebrain and spinal cord. Mol Cell Neurosci 2007; 35: 272-282.

4. De-Fraja C, Conti L, Magrassi L, Govoni S, Cattaneo E. Members of the JAK/STAT proteins are expressed and regulated during development in the mammalian forebrain. J Neurosci Res 1998; 54: 320-330.

5. Ting $\mathrm{CH}$, Lin CW, Wen SL, Hsieh-Li HM, Li H. Stat5 constitutive activation rescues defects in spinal muscular atrophy. Hum Mol Genet 2007; 16: 499-514.

6. Sirén AL, Fratelli M, Brines M, Goemans C, Casagrande S, Lewczuk P et al. Erythropoietin prevents neuronal apoptosis after cerebral ischemia and metabolic stress. Proc Nat Acad Sci USA 2001; 98: 4044-4049.

7. Um M, Lodish HF. Antiapoptotic effects of erythropoietin in differentiated neuroblastoma SH-SY5Y cells require activation of both the STAT5 and AKT signaling pathways. J Biol Chem 2006; 281: 5648-5656

8. Yu X, Shacka JJ, Eells JB, Suarez-Quian C, Przygodzki RM, Beleslin-Cokic B et al. Erythropoietin receptor signalling is required for normal brain development. Development 2002; 129: 505-516.

9. Zhang F, Wang S, Cao G, Gao Y, Chen J. Signal transducers and activators of transcription 5 contributes to erythropoietin-mediated neuroprotection against hippocampal neuronal death after transient global cerebral ischemia. Neurobiol Dis 2007; 25: 45-53. 
10. Liu J, Narasimhan P, Yu F, Chan PH. Neuroprotection by hypoxic preconditioning involves oxidative stress-mediated expression of hypoxia-inducible factor and erythropoietin. Stroke 2005; 36: 1264-1269.

11. Brines M, Cerami A. Emerging biological roles for erythropoietin in the nervous system. Nat Rev Neurosci 2005; 6: 484-494.

12. Shingo T, Sorokan ST, Shimazaki T, Weiss S. Erythropoietin regulates the in vitro and in vivo production of neuronal progenitors by mammalian forebrain neural stem cells. J Neurosci 2001; 21: 9733-9743.

13. Chong ZZ, Li F, Maiese K. Erythropoietin requires NF-kappaB and its nuclear translocation to prevent early and late apoptotic neuronal injury during beta-amyloid toxicity. Curr Neurovasc Res 2005; 2: 387-399.

14. Digicaylioglu M, Lipton SA. Erythropoietin-mediated neuroprotection involves cross-talk between Jak2 and NF-kappaB signalling cascades. Nature 2001; 412: 641-647.

15. Kilic E, Kilic U, Soliz J, Bassetti CL, Gassmann M, Hermann DM. Brain-derived erythropoietin protects from focal cerebral ischemia by dual activation of ERK-1/-2 and Ak pathways. FASEB J 2005; 19: 2026-2028.

16. Malhotra S, Savitz SI, Ocava L, Rosenbaum DM. Ischemic preconditioning is mediated by erythropoietin through $\mathrm{PI}-3$ kinase signaling in an animal model of transient ischemic attack. J Neurosci Res 2006; 83: 19-27.

17. Ruscher K, Freyer D, Karsch M, Isaev N, Megow D, Sawitzki B et al. Erythropoietin is a paracrine mediator of ischemic tolerance in the brain: evidence from an in vitro model. J Neurosci 2002; 22: 10291-10301.

18. Blaskovich MA, Sun J, Cantor A, Turkson J, Jove R, Sebti SM. Discovery of JSI-124 (cucurbitacin I), a selective Janus kinase/signal transducer and activator of transcription 3 signaling pathway inhibitor with potent antitumor activity against human and murine cancer cells in mice. Cancer Res 2003; 63: 1270-1279.

19. Sun J, Blaskovich MA, Jove R, Livingston SK, Coppola D, Sebti SM. Cucurbitacin Q: a selective STAT3 activation inhibitor with potent antitumor activity. Oncogene 2005; 24 3236-3245.

20. Klover $P$, Hennighausen $L$. Postnatal body growth is dependent on the transcription factors signal transducers and activators of transcription $5 \mathrm{a} / \mathrm{b}$ in muscle: a role for autocrine/ paracrine insulin-like growth factor I. Endocrinology 2007; 148: 1489-1497.

21. Kofoed EM, Hwa V, Little B, Woods KA, Buckway CK, Tsubaki J et al. Growth hormone insensitivity associated with a STAT5b mutation. N Engl J Med 2003; 349: 1139-1147.

22. Liu XB, Murray KD, Jones EG. Switching of NMDA receptor $2 A$ and $2 B$ subunits at thalamic and cortical synapses during early postnatal development. J Neurosci 2004; 24 8885-8895.

23. Brewer LD, Thibault O, Staton J, Thibault V, Rogers JT, Garcia-Ramos G et al. Increased vulnerability of hippocampal neurons with age in culture: temporal association with increases in NMDA receptor current, NR2A subunit expression and recruitment of L-type calcium channels. Brain Res 2007; 1151: 20-31.

24. Morishita E, Masuda S, Nagao M, Yasuda Y, Sasaki R. Erythropoietin receptor is expressed in rat hippocampal and cerebral cortical neurons, and erythropoietin prevents in vitro glutamate-induced neuronal death. Neuroscience 1997; 76: 105-116.
25. Silva C, Zhang K, Tsutsui S, Holden JK, Gill MJ, Power C. Growth hormone prevents human immunodeficiency virus-induced neuronal p53 expression. Ann Neurol 2003; 54 605-614.

26. Tschopp O, Yang ZZ, Brodbeck D, Dummler BA, Hemmings-Mieszczak M, Watanabe T et al. Essential role of protein kinase B gamma (PKB gamma/Akt3) in postnatal brain development but not in glucose homeostasis. Development 2005; 132: 2943-2954.

27. Yang ZZ, Tschopp O, Di-Poi N, Bruder E, Baudry A, Dummler B et al. Dosage-dependent effects of Akt1/protein kinase Balpha (PKBalpha) and Akt3/PKBgamma on thymus, skin and cardiovascular and nervous system development in mice. Mol Cell Biol 2005; 25 . 10407-10418.

28. Hardingham GE, Fukunaga $\mathrm{Y}$, Bading $\mathrm{H}$. Extrasynaptic NMDARs oppose synaptic NMDARs by triggering CREB shut-off and cell death pathways. Nat Neurosci 2002; 5 : 405-414.

29. Zhou M, Baudry M. Developmental changes in NMDA neurotoxicity reflect developmenta changes in subunit composition of NMDA receptors. J Neurosci 2006; 26: 2956-2963.

30. Meloni BP, Tilbrook PA, Boulos S, Arthur PG, Knuckey NW. Erythropoietin preconditioning in neuronal cultures: signaling, protection from in vitro ischemia, and proteomic analysis. J Neurosci Res 2006; 83: 584-593.

31. Grimm C, Wenzel A, Acar N, Keller S, Seeliger M, Gassmann M. Hypoxic preconditioning and erythropoietin protect retinal neurons from degeneration. Adv Exp Med Biol 2006; 588: $119-131$

32. Wen $\mathrm{X}$, Huang $\mathrm{Y}$, Wang J. Erythropoietin preconditioning on hippocampus neuronal apoptosis following status epilepticus induced by Li-pilocarpine in rats through anticaspase-3 expression. Neurol India 2006; 54: 58-63.

33. Carter-Su C, Rui L, Herrington J. Role of the tyrosine kinase JAK2 in signal transduction by growth hormone. Pediatr nephrol 2000; 14: 550-557.

34. Konishi Y, Chui DH, Hirose H, Kunishita T, Tabira T. Trophic effect of erythropoietin and other hematopoietic factors on central cholinergic neurons in vitro and in vivo. Brain Res 1993; 609: 29-35

35. Tabira T, Konishi Y, Gallyas Jr F. Neurotrophic effect of hematopoietic cytokines on cholinergic and other neurons in vitro. Int J Dev Neurosci 1995; 13: 241-252.

36. Wang L, Zhang ZG, Gregg SR, Zhang RL, Jiao Z, Letourneau Y et al. The sonic hedgehog pathway mediates carbamylated EPO enhanced proliferation and differentiation of adult neural progenitor cells. J Biol Chem 2007; 282: 32462-32470.

37. Wang L, Zhang Z, Wang Y, Zhang R, Chopp M. Treatment of stroke with erythropoietin enhances neurogenesis and angiogenesis and improves neurological function in rats. Stroke 2004; 35: 1732-1737.

38. Ransome MI, Goldshmit Y, Bartlett PF, Waters MJ, Turnley AM. Comparative analysis of CNS populations in knockout mice with altered growth hormone responsiveness. Eur Neurosci 2004; 19: 2069-2079.

39. Miller FD, Kaplan DR. Signaling mechanisms underlying dendrite formation. Curr Opin Neurobiol 2003; 13: 391-398.

40. Ludbrook J. Statistics in physiology and pharmacology: a slow and erratic learning curve. Clin Exp Pharmacol Physiol 2001; 28: 488-492. 